OPEN ACCESS

Edited by:

Amir H. Faraji,

Houston Methodist Hospital,

United States

Reviewed by:

Peter Woo,

Kwong Wah Hospital, Hong Kong,

SAR China

Alireza Mansouri,

The Pennsylvania State University

(PSU), United States

*Correspondence:

Max O. Krucoff

maxkrucoff@mcw.edu

Specialty section:

This article was submitted to

Neurosurgery,

a section of the journal

Frontiers in Surgery

Received: 24 June 2021 Accepted: 02 September 2021

Published: 01 October 2021

Citation:

Aaronson DM, Martinez Del Campo E. Boerger TF, Conway B, Cornell S,

Tate M, Mueller WM, Chang EF and Krucoff MO (2021) Understanding Variable Motor Responses to Direct Electrical Stimulation of the Human Motor Cortex During Brain Surgery.

Front. Surg. 8:730367.

doi: 10.3389/fsurg.2021.730367

\section{Understanding Variable Motor Responses to Direct Electrical Stimulation of the Human Motor Cortex During Brain Surgery}

\author{
Daniel M. Aaronson ${ }^{1}$, Eduardo Martinez Del Campo ${ }^{1}$, Timothy F. Boerger ${ }^{1}$, \\ Brian Conway ${ }^{2}$, Sarah Cornell ${ }^{1}$, Matthew Tate ${ }^{3}$, Wade M. Mueller ${ }^{1}$, Edward F. Chang ${ }^{4}$ and \\ Max O. Krucoff ${ }^{1,5 *}$ \\ ${ }^{1}$ Department of Neurosurgery, Medical College of Wisconsin, Milwaukee, WI, United States, ${ }^{2}$ Medical College of Wisconsin, \\ Milwaukee, WI, United States, ${ }^{3}$ Department of Neurosurgery, Feinberg School of Medicine, Northwestern University, \\ Chicago, IL, United States, ${ }^{4}$ Department of Neurosurgery, University of California, San Francisco, San Francisco, CA, \\ United States, ${ }^{5}$ Department of Biomedical Engineering, Marquette University, Milwaukee, WI, United States
}

Direct electrical stimulation of the brain is the gold standard technique used to define functional-anatomical relationships during neurosurgical procedures. Areas that respond to stimulation are considered "critical nodes" of circuits that must remain intact for the subject to maintain the ability to perform certain functions, like moving and speaking. Despite its routine use, the neurophysiology underlying downstream motor responses to electrical stimulation of the brain, such as muscle contraction or movement arrest, is poorly understood. Furthermore, varying and sometimes counterintuitive responses can be seen depending on how and where the stimulation is applied, even within the human primary motor cortex. Therefore, here we review relevant neuroanatomy of the human motor system, provide a brief historical perspective on electrical brain stimulation, explore mechanistic variations in stimulation applications, examine neurophysiological properties of different parts of the motor system, and suggest areas of future research that can promote a better understanding of the interaction between electrical stimulation of the brain and its function.

Keywords: brain mapping, motor cortex, cortical plasticity, brain stimulation, direct electrical stimulation (DES)

\section{INTRODUCTION}

The use of direct electrical stimulation (DES) of the human brain to define functional-anatomical relationships dates back to the very beginnings of modern neurosurgery (1). Currently, it is the gold standard technique used to map the brain's somatotopy and reduce the rate of postoperative neurological deficits in glioma and epilepsy surgeries (2). Areas of the brain that produce a response upon stimulation are considered gateway "critical nodes" into cerebral circuits that control functional movement and language. Although DES is used in neurosurgical procedures across the world (3-5), when a response is generated, the pathway from stimulus to effect is generally poorly understood. The neurophysiology of underlying how an electrical stimulus interacts with a given population of neurons can vary widely. Specifically, within the motor cortex, when stimulation induces local action potentials, the circuit modulation and downstream effects can result in silence, muscle activation, or motor inhibition. Over the course of the last century and a half, much 
has been learned about the mechanisms and neurophysiological properties of the motor system, cortical circuitry, and motor control. Despite these advances, there is still a limited understanding of how stimulation responses vary across individuals, pathologies, and stimulation parameters. Therefore, here we review relevant neuroanatomy of the human motor system, provide a brief historical perspective on electrical brain stimulation, explore mechanistic variations in stimulation applications, examine neurophysiological properties of different parts of the motor system, and suggest areas of future research that can promote a better understanding of the interaction between electrical stimulation of the brain and its function.

\section{MANUSCRIPT}

\section{A Brief History of Direct Electrical Brain Stimulation}

Direct electrical stimulation of cortical structures to investigate anatomical function has been used since the second half of the $19^{\text {th }}$ century in animals (6). Although the technology at the time was somewhat crude [i.e., the intensity of the stimulation was measured by subjective sensation when applied to the experimenter's tongue (7)], it was not long before translation to the first trial of cortical stimulation of a human by Robert Bartholow in 1874 (8). In this famous case of a patient with basal cell carcinoma and exposed brain, Bartholow inserted electrodes into parenchyma [likely Brodmann area 7 bilaterally (9)] and elicited contralateral muscle contractions reliably from both sides of the brain. Around the turn of the 20th century, this knowledge was put to practical neurosurgical applications by Horsley, Bidwell, Krause, and Cushing (1, 10-12), who continued to use this technique to expand the understanding of brain function over many years.

Initially, there was debate among scholars as to which areas of the cortex contributed to motor and sensory function and which areas did not. Some firmly believed motor and sensory function to be combined as one sensorimotor region, while others believed motor localization to be distinct and belong purely to the region anterior to the central sulcus $(13,14)$. A significant shift in theory was noted after the work of Grünbaum and Sherrington (13), which led to more a concrete model of an anatomically distinct pre-Rolandic motor cortex and post-Rolandic sensory cortex (15). Their work, along with contributions from Krause, was among the first to illustrate a somatotopic map of the motor cortex (12). Cushing reported using DES in his anesthetized patients (1) as early as 1902 (16), and soon after progressed to using the technique on awake patients, allowing him to interpret sensory information in the post-central gyrus as well (Figure 1).

In the mid-twentieth century, Penfield described the density of cortical organization through the visual representation of the sensorimotor homunculus (13). His work alongside Rasmussen continued to examine localization of cortical functions (17), and his work with Welch expanded knowledge of planning of

\footnotetext{
Abbreviations: DES, direct electrical stimulation; SMA, supplementary motor area; EMG, electromyography; NMR, negative motor response; NMA, negative motor area; PMR, positive motor response.
}

motor function in the anterior supplementary motor area (SMA), defining a region involved in complex movements and initiation of movements (18).

When Penfield and Rasmussen reported negative effects (e.g., inhibition and muscle relaxation) upon stimulating certain areas of the motor cortex, the nature of Brodmann area 6 began to be questioned once again (17). This finding led some to think motor planning and inhibition may also be involved in this region. Along the way, the model of the motor cortex began to evolve from a simplistic, positive response area whereby "a chain of neurons is activated and an effective impulse passes out to the periphery" (13), to include areas of planning and areas of negative responses resulting in motor inhibition (which will be further described later in this paper).

In sum, DES of the cortex has been the primary tool used to define cerebral anatomical-functional relationships (19) from Penfield's work on sensorimotor systems (20) to Ojemann's studies on language (21). In addition to its use as an investigational tool, it has also been a critical surgical tool used to outline functional-anatomical somatotopy and predict and minimize post-operative deficits. Throughout the 20th century and beyond, DES has become standard of care for patients undergoing resections of brain tumors (22) and epilepsy lesions (23) in eloquent motor and/or language systems (24-38).

\section{Relevant Anatomy of the Human Primary Motor System}

Neuronal cell bodies located in layer 5 of the primary motor cortex have axons that project down the corticobulbar and corticospinal tracts to either synapse directly onto motor neurons or interneurons of the brainstem and spinal cord (Figure 2) (39). Layer 5 neurons also have connections with other cortical and subcortical structures, ranging from association fibers to the somatosensory cortex to outputs to the direct and indirect pathways of the basal ganglia (40-42). Because of this complex network of connections, the sum of direct output from the primary motor cortex is not exclusively excitatory. Other nearby anterior motor regions, such as the SMA and premotor areas, as well as some posterior parietal regions, have been shown to be linked to generating intent to perform an action and ordering complex motor movements later effectuated by the motor cortex $(18,43-46)$. Additionally, there is evidence that the more anterior "planning regions" may have their own direct influence on the spinal cord (47), perhaps in parallel to the corticospinal tract (48). This evidence is consistent with primate experiments supporting a model where primary motor cortex neurons more directly encode muscle activity, or kinetics, to a greater extent than limb position or velocity, or kinematics (49). While the concept of these "anterior planning regions" is generally accepted, this is not a strict, linear hierarchy, as other frontal and parietal areas have been shown to participate in subcortical motor networks (48).

The primary motor cortex has been described as a discrete functional-anatomical interface along a unimodal gradient (50), meaning it is a cortical region with a somatotopic organization where movement intention is translated into action. This unimodal network gradient description may account for the more homogeneous, reproducible results of direct electrical 


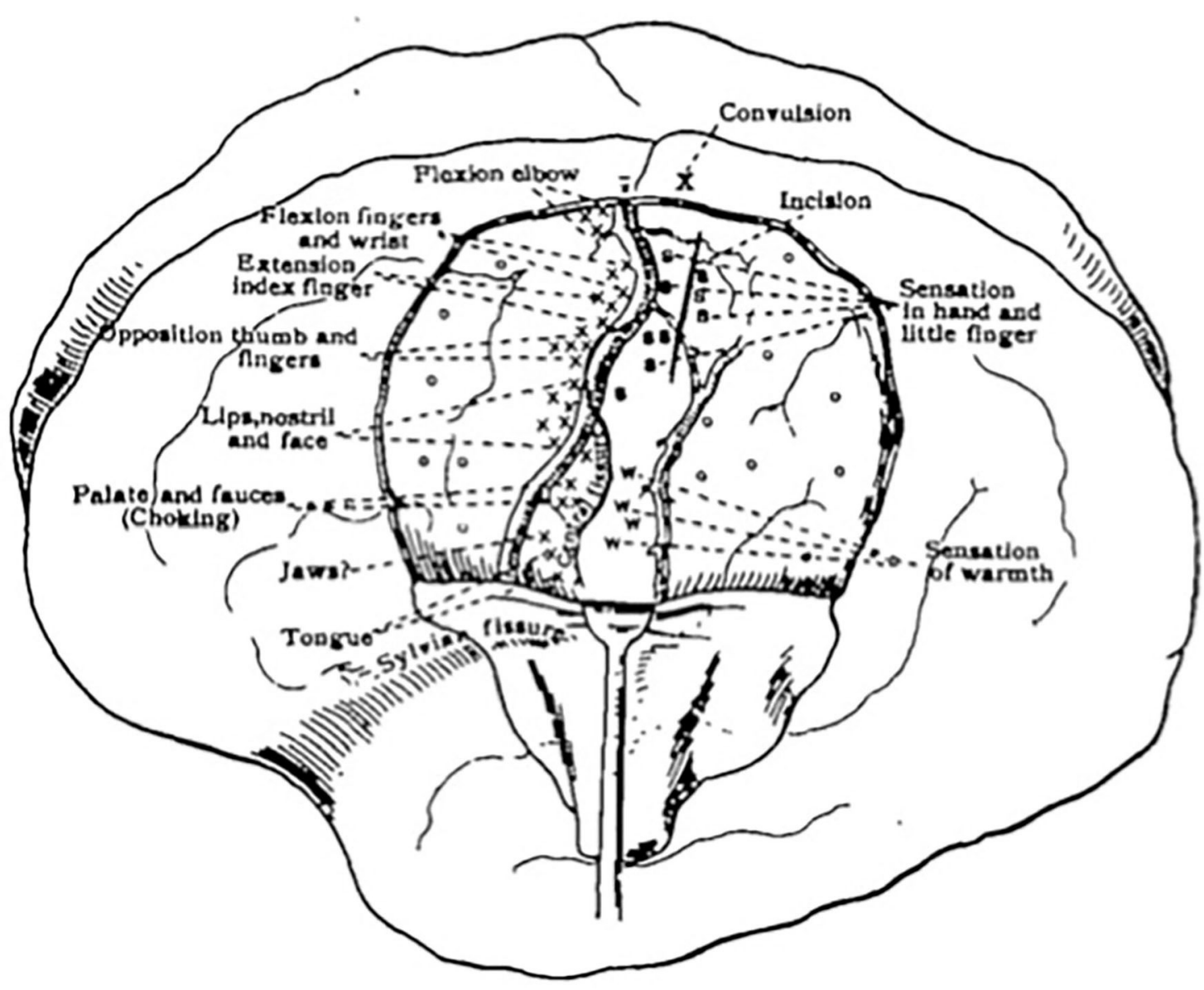

FIGURE 1 | First sketch mapping motor and sensory responses during an awake craniotomy. Reprinted from Cushing $\mathrm{H}$., A note upon the faradic stimulation of the postcentral gyrus in conscious patients, Brain, 1909;32(1):44-53 by permission of Oxford University Press.

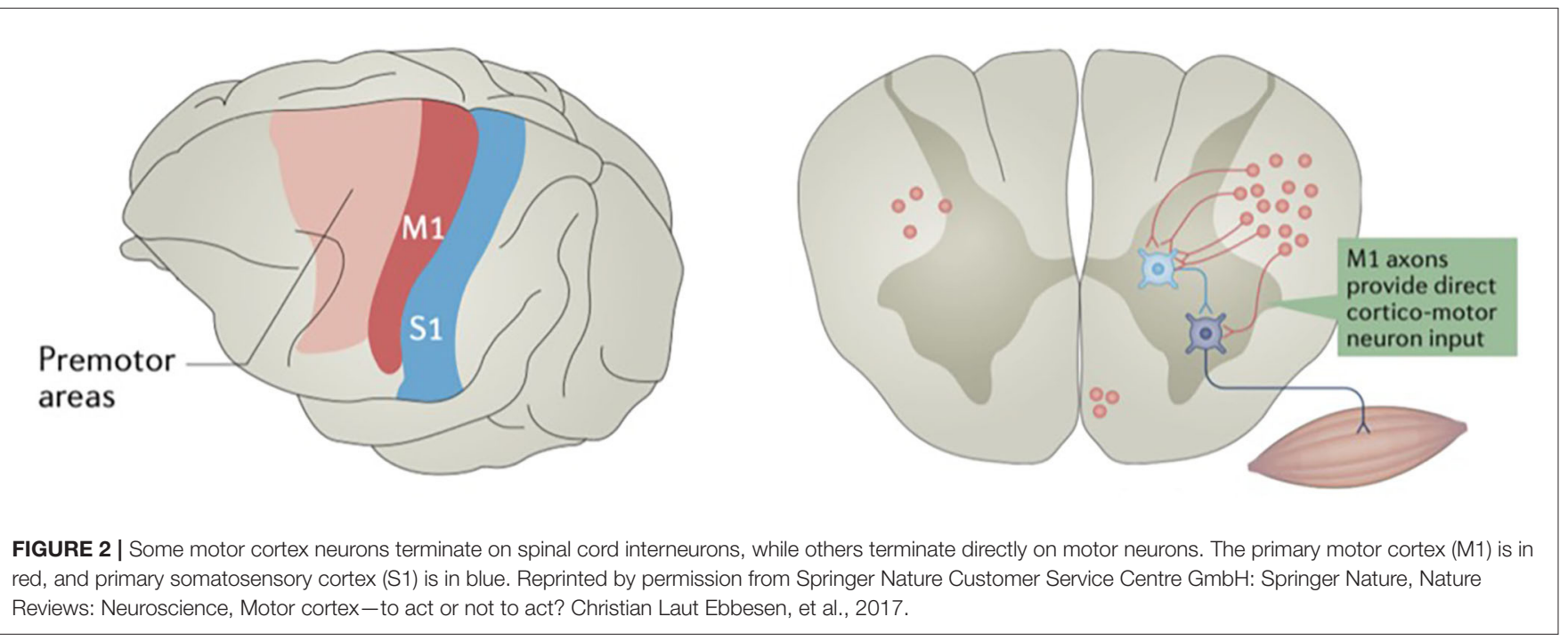

stimulation on the motor system (51) when compared with more transmodal networks like emotion and cognition, for example (50). However, studies of motor connectivity have shown both interindividual variability and plasticity in recovery from deficits (52), suggesting a neural network model that can modulate function in a dynamic fashion (19). This has been 
demonstrated specifically in the primary motor cortex in patients with infiltrating tumors $(53,54)$. In other words, in a static model, input A may always lead to output B; however, in a dynamic model, input A may lead to output B, or may lead to output $\mathrm{C}$, depending on inputs from other systems. Stimulation of the motor cortex to induce plasticity has also begun to be explored, showing that durable plastic changes in the motor cortex may also be artificially constructed for therapeutic applications (55).

\section{Modern Neurostimulation Techniques and Related Neurophysiology}

DES predominantly affects axons (56) by inducing a modulation in membrane potential through a directly applied electric current (57) that triggers a response. The downstream result of this stimulation can vary significantly and depends on a number of factors. Modifiable factors include the stimulating parameters (i.e., pulse type, width, frequency, and intensity) (58), probe configuration (i.e., monopolar or bipolar) (4), and anatomical location. Alterations in these variables can affect which cells are stimulated, to what extent they are stimulated, and what their response to that stimulation might be.

\section{Stimulation Parameters}

The effect of varying stimulation parameters on downstream motor function has not been systematically tested in humans to our knowledge. However, many studies do provide some insight into how certain stimulation parameters effect downstream effects. For example, stimulation amplitude can alter how cells behave by inducing hyperpolarization from large current delivery (59), and, as the current spreads from an electrode and charge drops over distance, the net effect may be hyperpolarization in the immediate vicinity of the electrode and initiation of action potentials at greater distances. Independent of current amplitude, inhibitory effects may also be induced through indirect signal propagation through cortical interneurons (60).

In addition to current amplitude, changing the frequency of stimulation has been shown to modulate neuronal activity. One study (58) found that lower frequency stimulation (i.e., 10$50 \mathrm{~Hz}$ ) was more likely to cause neuronal suppression, whereas higher frequency stimulation (i.e., $100-200 \mathrm{~Hz}$ ) was more likely to lead to neuronal activation. The authors of this study proposed that lower frequency stimulation may activate passing axons, whereas higher frequency stimulation activates cell bodies, thus accounting for the difference. It should be noted, however, that the neuronal activation measured in this study was high frequency activation [HFA] of neurons, not downstream motor function (i.e., hand movement or speech activation).

Environmental factors may also alter the interface through which the current is delivered. For example, the pia matter itself has significant resistance and capacitance that can alter stimulation, which changes over the amount of time exposed to air (61). In theory, these changes could lead to the delivery of different currents over the duration of an operation despite using the same stimulation parameters at the same location. While the intention may be to stimulate a focal region only, the end result may be the stimulation of "an unknown number and unknown kinds of cells at unknown locations in the vicinity of the electrode" (59).

\section{Bipolar vs. Monopolar Stimulation}

The original technique introduced by Penfield involving bipolar stimulation at a frequency between $50-60 \mathrm{~Hz}$ delivered in long trains (1-4s) of biphasic pulses remains the gold standard in neurosurgical practice $(24,35,62)$. More recent developments include a monopolar technique first described by Taniguchi et al. in 1993 that instead uses a train of 5-10 short pulses $(10-18 \mathrm{~ms})$ at higher frequencies of $250-500 \mathrm{~Hz}(63,64)$. Also known as the "train-of-five," this technique has been popularized in recent years by Szelényi et al. (64) and Bello et al. (65), as it has shown higher sensitivity in identifying motor pathways (64, 66-68) with equal safety and efficacy when compared to bipolar stimulation techniques (69). Some surgeons have chosen to combine both bipolar stimulation, for maximal definitive resolution, with monopolar stimulation, for sensitivity and estimation of distance to motor pathways, to maximize the advantages from both modalities $(64,66)$, and the addition of concurrent motor evoked potential monitoring has been termed "triple motor mapping" (66).

While traditional DES implies cortical surface stimulation, the advent of subcortical mapping in the late $20^{\text {th }}$ century has also proven quite useful $(26,27,30,33,48,62,70,71)$. Subcortical mapping evaluates for white matter involvement throughout the duration of the surgery, and allows the surgeon to safely resect tissue deep to the cortex without violating irreparable tracts. A recent method introduced by Yamaguchi et al. (72) utilizes a neuronavigated bipolar stimulator with needle-tipped electrodes that can be inserted directly into subcortical tissue. This stimulator aims to minimize conduction through heterogenous tissue which may alter delivery of the stimulation current. The stimulator was coupled with plastic tubes which could be left in situ as "fence post markers" to aid in establishing neuronavigated and stimulation-confirmed white matter borders prior to brain shift from tumor resection.

\section{Variable Downstream Motor Effects}

Motor effects can be monitored by visual observation of motor end phenomenon or continuous electromyography (EMG) monitoring (73). Patients must not be chemically paralyzed to observe end motor phenomenon, and anesthetic agents and doses can play a role in the sensitivity and success of motor mapping (74-77).

Historically, responses to direct stimulation of the cortex have been divided into two broad categories, as described by Duffau (19):

1) A "positive motor response" (PMR), in which a neurologic downstream effect is actuated in a resting state, such as a sum excitatory signal causing muscle contraction.

2) A "negative motor response" (NMR), in which there is inhibition of an intended action, such as induced aphasia or arrest of a repeated action.

When DES results in an NMR, or inhibition of movement without loss of consciousness, this stimulated cortical region 
is referred to as a negative motor area (NMA) (78). This phenomenon is distinct from activation and contraction of an opposing muscle group, which would still be considered a PMR. While NMAs were previously thought to be either distributed widely along the lateral aspect of a given cortical hemisphere (79-81) or somatotopically located in the inferior frontal gyrus (82), more recent work shows NMAs to be more reliably located in several areas within the precentral gyrus (83), although not exclusively (84). In general, NMAs appear to localize in two main regions, a more medial region which includes the SMA and pre-SMA regions, and a more lateral region which includes the inferior frontal gyrus and the premotor cortex (80). Additional NMAs with clinical relevance include those in the parietal lobe, stimulation of which can lead to hand apraxia (85), for which specific hand-motor tasks can be monitored during DES to avoid post-operative deficits (86).

The mechanism by which NMRs are generated is not yet understood, and there are different viewpoints represented in the literature. Mikuni et al. (79) suggests these NMRs represent external disruption of physiologically excitatory pathways. A similar mechanism has been proposed by Duffau et al., who categorized these NMRs as a "second intermediate level" of functional disturbance due to DES, namely that the task inhibition is due to disruption of a subcircuit network (19). Others have postulated the NMRs represent activation of naturally encoded inhibitory pathways within, or relating to, the motor cortex (87). This has been supported by fMRI studies which have shown motor region activation patterns for muscle relaxation to be similar to activation patterns for muscle contraction (88), with accompanying evidence that these processes are driven by an excitatory, active process as opposed to neuronal suppression $(89,90)$.

In addition to underlying anatomical physiology, widespread heterogeneity in how DES has been applied may account for some differences in results. In Mikuni et al.'s study, for example, stimulation was performed at $50 \mathrm{~Hz}$ in square waves of alternating polarity with $0.3 \mathrm{~ms}$ duration for 1 to $5 \mathrm{~s}$ between subdural electrodes with intensity ranging between 2 and $15 \mathrm{~mA}$. They found regions where a low stimulation intensity would trigger a NMRs, while higher intensity stimulation in the same region could then induce a PMR (79). More recent studies by Rech et al., however, only stimulated at lower intensities (on the range of $2 \mathrm{~mA}$ ) due to time constraints at $60 \mathrm{~Hz}$ with biphasic current and $1 \mathrm{~ms}$ pulse width for $4 \mathrm{~s}$ via a bipolar electrode with tip width set at $5 \mathrm{~mm}$, finding no NMAs that eventually produced a PMR (83). This may be due to modulation of the neuronal population recruited in the NMA based on electrophysiological response or could alternatively be explained by a wider recruitment field including PMR-controlling neurons with higher intensity, as increased current travels over larger distances. Ultimately, the gap in understanding the effects of varying stimulation parameters in certain anatomical locations on downstream motor systems outlines the need for future studies in this area.

\section{Translation to Clinical Practice}

While DES is undeniably the goal standard to intraoperatively map functional-anatomical somatotopy of the motor system, current DES techniques vary widely. Controversies include awake vs. asleep mapping, complex tasks (i.e., apraxia) vs. simple motor response mapping, bipolar vs. monopolar stimulation, high vs. low frequency stimulation, continuous motor evoked potentials vs. repeated intraoperative stimulation, length and type of stimulus pattern, and gray vs. subcortical mapping. As discussed above, there is a general movement to combine these modalities into more nuanced mapping/resection strategies, as opposed to using one vs. the other. While bipolar stimulation at $50-60 \mathrm{~Hz}$ has been the most widely employed method for mapping the motor cortex, advantages to high frequency monopolar stimulation may include fewer intraoperative seizures and increased sensitivity $(64,66-68)$. While there is evidence to support this claim, it has not yet been widely adopted as a cortical stimulation technique. When performing subcortical stimulation in descending motor pathways, the use of a train of multiple highfrequency monopolar stimulation pulses at $250-500 \mathrm{~Hz}$ may afford the surgeon similar advantages. In one series, the addition of monopolar stimulation to standard bipolar stimulation for the subcortical regions increased identification of descending motor pathways from 30 to $86.4 \%$ (66), similar to Szelényi et al.'s work which improved sensitivity from $54 \%$ using bipolar to $92 \%$ using monopolar stimulation (65). As mentioned prior, some have chosen to combine bipolar and monopolar stimulation with concurrent motor evoked potential monitoring, termed "triple motor mapping" (66).

Advantages to awake intraoperative mapping include surgeon confidence in the patient's neurological status, fewer intraoperative technical nuances obscuring the meaning of signal loss, and the ability to map more complex motor, cognitive, sensory, and speech-language systems. Disadvantages include patient discomfort and false negative exam responses due to, for example, development of an intraoperative SMA syndrome leading to a smaller extent of resection. Multiple studies have sought to evaluate outcome differences in awake vs. asleep motor mapping; however, the amalgamation of the available evidence does not support one technique over the other. Ultimately, decisions on how to intraoperatively map the motor system across neurosurgical operating rooms will depend on the specifics of case, including surgeon experience, patient goals and abilities, and other necessary functional assessments (i.e., language). The authors do generally advocate a trend toward using bipolar stimulation on the cortex, high frequency monopolar stimulation on the subcortical white matter, and continuous motor evoked potentials during resection wherever possible. Also, for pure motor cases, the authors generally prefer asleep mapping to prevent false positive exam changes from phenomenae such as SMA syndrome that might prematurely conclude the surgery, with the caveat of trending toward awake mapping when more complex task monitoring is needed (i.e., apraxia and/or speech-language). 


\section{CONCLUSION}

Systematic stimulation parameter testing in the motor cortex is needed. Additionally, there is much discrepancy in both the definition and locations of NMAs, and developing more objective ways of measuring and detailing motor function and inhibitory effects during stimulation would make this type of testing more broadly applicable. Also, the application of more chronic types of stimulation in ambulatory patients and their potential to modulate neuronal circuits are becoming more widely available (91). With the development of FDA-approved, chronically implanted devices that can both sense neuronal signals and stimulate the cortex, new ambulatory recordings and stimulation-plasticity induction techniques may follow $(92,93)$. Additionally, progress is being made in non-invasive techniques of cortical stimulation, specifically with navigated transcranial magnetic stimulation (TMS), which is being used in certain centers to augment and/or predict DES findings (94).

DES is an important tool to investigate anatomical-functional relationships in neurosurgical practice. Electrical stimulation of the motor cortex in the literature is heterogeneously applied, and care must be taken in interpreting results as differences in stimulation techniques, anatomical applications, underlying pathologies, and patient populations may impact the results.

\section{REFERENCES}

1. Cushing $\mathrm{H}$. A note upon the faradic stimulation of the postcentral gyrus in conscious patients. Brain. (1909) 32:44-53. doi: 10.1093/brain/32. 1.44

2. Morshed RA, Young JS, Lee AT, Berger MS, Hervey-Jumper SL. Clinical pearls and methods for intraoperative awake language mapping. Neurosurgery. (2020) 89:143-53. doi: 10.1093/neuros/nyaa440

3. Beez T, Boge K, Wager M, Whittle I, Fontaine D, Spena G, et al. Tolerance of awake surgery for glioma: a prospective European low grade glioma network multicenter study. Acta Neurochir. (2013) 155:1301-8. doi: 10.1007/s00701-013-1759-0

4. Szelenyi A, Bello L, Duffau H, Fava E, Feigl GC, Galanda M, et al. Workgroup for intraoperative management in low-grade glioma surgery within the European low-grade glioma, intraoperative electrical stimulation in awake craniotomy: methodological aspects of current practice. Neurosurg Focus. (2010) 28:E7. doi: 10.3171/2009.12.FOCUS09237

5. Sanai N, Berger MS. Intraoperative stimulation techniques for functional pathway preservation and glioma resection. Neurosurg Focus. (2010) 28:E1. doi: 10.3171/2009.12.FOCUS09266

6. Fritsch G. Uber die elektrische Erregbarkeit des Grosshirns. Arch, anat Physiol Wiss Med. (1870) 37:300-32.

7. Rothwell J, Thompson P, Day B, Boyd S, Marsden C. Stimulation of the human motor cortex through the scalp. Exp Physiol. (1991) 76:159-200. doi: 10.1113/expphysiol.1991.sp003485

8. Bartholow R. ART. I.-experimental investigations into the functions of the human brain. Am J Med Sci. (1874) 34:305. doi: 10.1097/00000441-187404000-00001

9. Harris LJ, Almerigi JB. Probing the human brain with stimulating electrodes: the story of roberts bartholow's (1874) experiment on mary rafferty. Brain Cogn. (2009) 70:92-115. doi: 10.1016/j.bandc.2009.01.008

10. Horsley V. Case of occipital encephalocele in which a correct diagnosis was obtained by means of the induced current. Brain. (1884) 7:228-43. doi: 10.1093/brain/7.2.228

11. Bidwell LA. Focal epilepsy: trephining and removal of small haemorrhagic focus: no improvement; removal of part of leg centre
As described above, stimulation parameters, recruitment of nearby cells, membrane potential changes, and the parts of the cell stimulated can all change the functional outcomes of a given stimulated region. Furthermore, motor circuits are not a simple unimodal hierarchy of neurons. DES may effectuate inhibitory subcortical interneurons, modulation circuits, or spinal interneuron circuits as well as corticospinal tracts. Lastly, stimulation can induce both positive and negative motor responses, depending on both the stimulation location and input parameters. Variance in a multitude of these parameters may lead to alterations in downstream motor outcome, which may also change over time due transitory changes in connectivity across multiple neural networks. Therefore, the motor cortex may be best described as "an input gate into a large-scale network" (95), rather than as an isolated discrete functional site. Future studies systematically varying stimulation parameters, anatomical locations, and downstream effects are needed.

\section{AUTHOR CONTRIBUTIONS}

DA and MK contributed to the conception, design and wrote sections of the manuscript. DA wrote the first draft. All authors contributed to manuscript revision, read, and approved the submitted version. after electrical stimulation: improvement. Br Med J. (1893) 2:988. doi: $10.1136 / \mathrm{bmj} .2 .1714 .988$

12. Krause F. Die operative behandlung der epilepsie. Med Klin. (1909) 5:1418-22.

13. Penfield W, Boldrey E. Somatic motor and sensory representation in the cerebral cortex of man as studied by electrical stimulation. Brain. (1937) 60:389-443. doi: 10.1093/brain/60.4.389

14. de Barenne JD. Central levels of sensory integration. Arch Neurol Psych. (1935) 34:768-76. doi: 10.1001/archneurpsyc.1935.02250220072007

15. Grünbaum AS. Sherrington CS. Observations on the physiology of the cerebral cortex of some of the higher apes(Preliminary communication). Proc R Soc Lond. (1901) 69:206-9. doi: 10.1098/rspl.1901.0100

16. Pendleton C, Zaidi HA, Chaichana KL, Raza SM, Carson BS, Cohen-Gadol AA, et al. Harvey cushing's contributions to motor mapping: 1902-1912. Cortex. (2012) 48:7-14. doi: 10.1016/j.cortex.2010.04.006

17. Penfield W, Rasmussen T. The cerebral cortex of man; a clinical study of localization of function. JAMA. (1950) 144:1412.

18. Penfield W, Welch K. The supplementary motor area of the cerebral cortex; a clinical and experimental study. AMA Arch Neurol Psychiatry. (1951) 66:289317. doi: 10.1001/archneurpsyc.1951.02320090038004

19. Duffau $H$. What direct electrostimulation of the brain taught us about the human connectome: a three-level model of neural disruption. Front Hum Neurosci. (2020) 14:315. doi: 10.3389/fnhum.2020.00315

20. Penfield W, Jasper H. Epilepsy and the Functional Anatomy of the Human Brain. Boston: Little, Brown and Company. (1954). doi: 10.1097/00007611-195407000-00024

21. Ojemann G, Ojemann J, Lettich E, Berger M. Cortical language localization in left, dominant hemisphere. an electrical stimulation mapping investigation in 117 patients. J Neurosurg. (1989) 71:316-26. doi: 10.3171/jns.1989.71.3.0316

22. Berger MS. Functional mapping-guided resection of low-grade gliomas. Clin Neurosurg. (1995) 42:437-52.

23. Awad IA, Rosenfeld J, Ahl J, Hahn JF, Luders H. Intractable epilepsy and structural lesions of the brain: mapping, resection strategies, and seizure outcome. Epilepsia. (1991) 32:179-86. doi: 10.1111/j.1528-1157.1991.tb05242.x

24. Berger MS, Rostomily RC. Low grade gliomas: functional mapping resection strategies, extent of resection, and outcome. J Neurooncol. (1997) 34:85-101. 
25. Chang EF, Clark A, Smith JS, Polley MY, Chang SM, Barbaro NM, et al. Functional mapping-guided resection of low-grade gliomas in eloquent areas of the brain: improvement of long-term survival. clinical article. J Neurosurg. (2011) 114:566-73. doi: 10.3171/2010.6.JNS091246

26. Duffau H. Intraoperative cortico-subcortical stimulations in surgery of low-grade gliomas. Expert Rev Neurother. (2005) 5:473-85. doi: 10.1586/14737175.5.4.473

27. Duffau H, Capelle L, Denvil D, Sichez N, Gatignol P, Taillandier L, et al. Usefulness of intraoperative electrical subcortical mapping during surgery for low-grade gliomas located within eloquent brain regions: functional results in a consecutive series of 103 patients. J Neurosurg. (2003) 98:764-78. doi: $10.3171 /$ jns.2003.98.4.0764

28. Duffau H, Lopes M, Arthuis F, Bitar A, Sichez J, Van Effenterre R, et al. Contribution of intraoperative electrical stimulations in surgery of low grade gliomas: a comparative study between two series without (1985-96) and with (1996-2003) functional mapping in the same institution. J Neurol Neurosurg Psychiatry. (2005) 76:845-51. doi: 10.1136/jnnp.2004.048520

29. Hamer DWP, Robles SG, Zwinderman AH, Duffau H, Berger MS. Impact of intraoperative stimulation brain mapping on glioma surgery outcome: a metaanalysis. J Clin Oncol. (2012) 30:2559-65. doi: 10.1200/JCO.2011.38.4818

30. Han SJ, Morshed RA, Troncon I, Jordan KM, Henry RG, Hervey-Jumper SL, et al. Subcortical stimulation mapping of descending motor pathways for perirolandic gliomas: assessment of morbidity and functional outcome in 702 cases. J Neurosurg. (2018) 131:201-8. doi: 10.3171/2018.3.JNS172494

31. Hardesty DA, Sanai N. The value of glioma extent of resection in the modern neurosurgical era. Front Neurol. (2012) 3:140. doi: 10.3389/fneur.2012.00140

32. Hess KR. Extent of resection as a prognostic variable in the treatment of gliomas. J Neurooncol. (1999) 42:227-31. doi: 10.1023/A:1006118018770

33. Keles GE, Lundin DA, Lamborn KR, Chang EF, Ojemann G, Berger MS. Intraoperative subcortical stimulation mapping for hemispheric perirolandic gliomas located within or adjacent to the descending motor pathways: evaluation of morbidity and assessment of functional outcome in 294 patients. J Neurosurg. (2004) 100:369-75. doi: 10.3171/jns.2004.100.3.0369

34. Sanai N, Berger MS. Glioma extent of resection and its impact on patient outcome. Neurosurgery. (2008) 62:753-64. doi: 10.1227/01.neu.0000318159.21731.cf

35. Sanai N, Berger MS. Operative techniques for gliomas and the value of extent of resection. Neurotherapeutics. (2009) 6:478-86. doi: 10.1016/j.nurt.2009.04.005

36. Senft C, Bink A, Franz K, Vatter H, Gasser T, Seifert V. Intraoperative MRI guidance and extent of resection in glioma surgery: a randomised, controlled trial. Lancet Oncol. (2011) 12:997-1003. doi: 10.1016/S1470-2045(11)70196-6

37. Smith JS, Chang EF, Lamborn KR, Chang SM, Prados MD, Cha S, et al. Role of extent of resection in the long-term outcome of low-grade hemispheric gliomas. J Clin Oncol. (2008) 26:1338-45. doi: 10.1200/JCO.2007.13.9337

38. Winger MJ, Macdonald DR, Cairncross JG. Supratentorial anaplastic gliomas in adults. The prognostic importance of extent of resection and prior lowgrade glioma. J Neurosurg. (1989) 71:487-93. doi: 10.3171/jns.1989.71.4.0487

39. Ebbesen CL, Brecht M. Motor cortex-to act or not to act? Nature Rev Neurosci. (2017) 18:694-705. doi: 10.1038/nrn.2017.119

40. Albin RL, Young AB, Penney JB. The functional anatomy of basal ganglia disorders. Trends Neurosci. (1989) 12:366-75. doi: 10.1016/0166-2236(89)90074-X

41. Freeze BS, Kravitz AV, Hammack N, Berke JD, Kreitzer AC. Control of basal ganglia output by direct and indirect pathway projection neurons. J Neurosci. (2013) 33:18531-9. doi: 10.1523/JNEUROSCI.1278-13.2013

42. Calabresi P, Picconi B, Tozzi A, Ghiglieri V, Di Filippo M. Direct and indirect pathways of basal ganglia: a critical reappraisal. Nat Neurosci. (2014) 17:102230. doi: 10.1038/nn.3743

43. Deecke L, Scheid P, Kornhuber HH. Distribution of readiness potential, pre-motion positivity, and motor potential of the human cerebral cortex preceding voluntary finger movements. Exp Brain Res. (1969) 7:158-68. doi: 10.1007/BF00235441

44. Roland PE, Larsen B, Lassen NA, Skinhoj E. Supplementary motor area and other cortical areas in organization of voluntary movements in man. J Neurophysiol. (1980) 43:118-36. doi: 10.1152/jn.1980.43.1.118

45. Tanji J, Shima K. Role for supplementary motor area cells in planning several movements ahead. Nature. (1994) 371:413-6. doi: 10.1038/371413a0
46. Makoshi Z, Kroliczak G, van Donkelaar P. Human supplementary motor area contribution to predictive motor planning. J Mot Behav. (2011) 43:303-9. doi: 10.1080/00222895.2011.584085

47. Dum RP, Strick PL. The origin of corticospinal projections from the premotor areas in the frontal lobe. J Neurosci. (1991) 11:667-89. doi: 10.1523/JNEUROSCI.11-03-00667.1991

48. Schucht P. Moritz-Gasser S, Herbet G, Raabe A, Duffau H. Subcortical electrostimulation to identify network subserving motor control. Hum Brain Mapp. (2013) 34:3023-30. doi: 10.1002/hbm.22122

49. Cherian A, Krucoff MO, Miller LE. Motor cortical prediction of EMG: evidence that a kinetic brain-machine interface may be robust across altered movement dynamics. J Neurophysiol. (2011) 106:564-75. doi: 10.1152/jn.00553.2010

50. Margulies DS, Ghosh SS, Goulas A, Falkiewicz M, Huntenburg JM, Langs $\mathrm{G}$, et al. Situating the default-mode network along a principal gradient of macroscale cortical organization. Proc Natl Acad Sci U S A. (2016) 113:125749. doi: 10.1073/pnas.1608282113

51. Fox CRK, Shi L, Baek S, Raccah O, Foster BL, Saha S, et al. Intrinsic network architecture predicts the effects elicited by intracranial electrical stimulation of the human brain. Nat Hum Behav. (2020) 4:1039-52. doi: 10.1038/s41562-020-0910-1

52. Duffau H. Lessons from brain mapping in surgery for low-grade glioma: insights into associations between tumour and brain plasticity. Lancet Neurol. (2005) 4:476-86. doi: 10.1016/S1474-4422(05)70140-X

53. Kong NW, Gibb WR, Badhe S, Liu BP, Tate MC. Plasticity of the primary motor cortex in patients with primary brain tumors. Neural Plast. (2020) 2020:3648517. doi: 10.1155/2020/3648517

54. Gibb WR, Kong NW, Tate MC. Direct evidence of plasticity within human primary motor and somatosensory cortices of patients with glioblastoma. Neural Plasticity. (2020) 2020:1-7. doi: 10.1155/2020/8893708

55. Rivera-Rivera PA, Rios-Lago M, Sanchez-Casarrubios S, Salazar O, Yus M, Gonzalez-Hidalgo $\mathrm{M}$, et al. Cortical plasticity catalyzed by prehabilitation enables extensive resection of brain tumors in eloquent areas. J Neurosurg. (2017) 126:1323-33. doi: 10.3171/2016.2.JNS152485

56. Nowak L, Bullier J. Axons, but not cell bodies, are activated by electrical stimulation in cortical gray matter I. evidence from chronaxie measurements. Exp Brain Res. (1998) 118:477-88. doi: 10.1007/s002210050304

57. Vincent M, Rossel O, Hayashibe M, Herbet G, Duffau H, Guiraud D, et al. The difference between electrical microstimulation and direct electrical stimulation-towards new opportunities for innovative functional brain mapping? Rev Neurosci. (2016) 27:231-58. doi: 10.1515/revneuro-2015-0029

58. Mohan UR, Watrous AJ, Miller JF, Lega BC, Sperling MR, Worrell GA, et al. The effects of direct brain stimulation in humans depend on frequency, amplitude, and white-matter proximity. Brain Stimul. (2020) 13:1183-95. doi: 10.1016/j.brs.2020.05.009

59. Ranck JB. Which elements are excited in electrical stimulation of mammalian central nervous system: a review. Brain Res. (1975) 98:417-40. doi: 10.1016/0006-8993(75)90364-9

60. Krnjevic K, Randic M, Straughan DW. Nature of a cortical inhibitory process. J Physiol. (1966) 184:49-77. doi: 10.1113/jphysiol.1966.sp007903

61. Bennett MV. Electrical impedance of brain surfaces. Brain Res. (1969) 15:58490. doi: 10.1016/0006-8993(69)90191-7

62. Duffau H, Peggy Gatignol ST, Mandonnet E, Capelle L, Taillandier L. Intraoperative subcortical stimulation mapping of language pathways in a consecutive series of 115 patients with Grade II glioma in the left dominant hemisphere. J Neurosurg. (2008) 109:461-71. doi: 10.3171/JNS/2008/109/9/0461

63. Taniguchi M, Cedzich C, Taniguchi M, Cedzich C, Schramm J. Modification of cortical stimulation for motor evoked potentials under general anesthesia: technical description. Neurosurgery. (1993) 32:219-26. doi: 10.1097/00006123-199302000-00011

64. Bello L, Riva M, Fava E, Ferpozzi V, Castellano A, Raneri F, et al. Tailoring neurophysiological strategies with clinical context enhances resection and safety and expands indications in gliomas involving motor pathways. Neuro Oncol. (2014) 16:1110-28. doi: 10.1093/neuonc/not327

65. Szelényi A, Senft C, Jardan M, Forster M, Franz K, Seifert V, et al. Intraoperative subcortical electrical stimulation: a comparison of two methods. Clin Neurophysiol. (2011) 122:1470-5. doi: 10.1016/j.clinph.2010.12.055 
66. Gogos AJ, Young JS, Morshed RA, Avalos LN, Noss RS, Villanueva-Meyer JE, et al. Triple motor mapping: transcranial, bipolar, and monopolar mapping for supratentorial glioma resection adjacent to motor pathways. J Neurosurg. (2020) 1:1-10. doi: 10.3171/2020.3.JNS193434

67. Rossi M, Nibali MC, Viganò L, Puglisi G, Howells H, Gay L, et al. Resection of tumors within the primary motor cortex using highfrequency stimulation: oncological and functional efficiency of this versatile approach based on clinical conditions. J Neurosurg. (2019) 133:642-54. doi: $10.3171 / 2019.5$.JNS19453

68. Kombos T, Suess O. B.-Kern C, Funk T, Hoell T, Kopetsch O, et al. Comparison between monopolar and bipolar electrical stimulation of the motor cortex. Acta Neurochir. (1999) 141:1295-301. doi: 10.1007/s007010050433

69. Tate MC, Guo L, McEvoy J, Chang EF. Safety and efficacy of motor mapping utilizing short pulse train direct cortical stimulation. Stereotact Funct Neurosurg. (2013) 91:379-85. doi: 10.1159/000350020

70. Sarubbo S, Annicchiarico L, Corsini F, Zigiotto L, Herbet G, Moritz-Gasser S, et al. Planning brain tumor resection using a probabilistic atlas of cortical and subcortical structures critical for functional processing: a proof of concept. Oper Neurosurg. (2020) 20:E175-E183. doi: 10.1093/ons/opaa396

71. Rech F, Herbet G, Moritz-Gasser S, Duffau H. Disruption of bimanual movement by unilateral subcortical electrostimulation. Hum Brain Mapp. (2014) 35:3439-45. doi: 10.1002/hbm.22413

72. Yamaguchi F, Ten H, Higuchi T, Omura T, Kojima T, Adachi K, et al. An intraoperative motor tract positioning method in brain tumor surgery. $J$ Neurosurg. (2017) 129:576-82. doi: 10.3171/2017.5.JNS162978

73. Yingling CD, Ojemann S, Dodson B, Harrington MJ, Berger MS. Identification of motor pathways during tumor surgery facilitated by multichannel electromyographic recording. J Neurosurg. (1999) 91:922-7. doi: 10.3171/jns.1999.91.6.0922

74. Sacko O, Lauwers-Cances V, Brauge D, Sesay M, Brenner A. F.Roux E. Awake craniotomy vs surgery under general anesthesia for resection of supratentorial lesions. Neurosurgery. (2011) 68:1192-9. doi: 10.1227/NEU.0b013e31820c02a3

75. Ott C, Kerscher C, Luerding R, Doenitz C, Hoehne J, Zech N, et al. The impact of sedation on brain mapping: a prospective, interdisciplinary, clinical trial. Neurosurgery. (2014) 75:117-23. doi: 10.1227/NEU.0000000000000359

76. Ohtaki S, Akiyama Y, Kanno A, Noshiro S, Hayase T, Yamakage $\mathrm{M}$, et al. The influence of depth of anesthesia on motor evoked potential response during awake craniotomy. J Neurosurg. (2017) 126:260-5. doi: 10.3171/2015.11.JNS151291

77. Zelitzki R, Korn A, Arial E, Ben-Harosh C, Ram Z, Grossman R. Comparison of motor outcome in patients undergoing awake vs general anesthesia surgery for brain tumors located within or adjacent to the motor pathways. Neurosurgery. (2019) 85:E470-6. doi: 10.1093/neuros/ nyz007

78. H. Lüders, Lesser R, Morris H. Negative motor responses elicited by stimulation of the human cortex. Advances in epileptology. New York, NY: Raven Press (1987).

79. Mikuni N, Ohara S, Ikeda A, Hayashi N, Nishida N, Taki J, et al. Evidence for a wide distribution of negative motor areas in the perirolandic cortex. Clin Neurophysiol. (2006) 117:33-40. doi: 10.1016/j.clinph.2005.08.021

80. Filevich E, Kuhn S, Haggard P. Negative motor phenomena in cortical stimulation: implications for inhibitory control of human action. Cortex. (2012) 48:1251-61. doi: 10.1016/j.cortex.2012.04.014

81. Borggraefe I, Catarino CB, Remi J, Vollmar C, Peraud A, Winkler PA, et al. Lateralization of cortical negative motor areas. Clin Neurophysiol. (2016) 127:3314-21. doi: 10.1016/j.clinph.2016.08.001

82. Luders HO, Dinner DS, Morris HH, Wyllie E, Comair YG. Cortical electrical stimulation in humans. the negative motor areas. Adv Neurol. (1995) 67:115-29.

83. Rech F, Herbet G, Gaudeau Y, Mezieres S, Moureau JM, Moritz-Gasser S, et al. A probabilistic map of negative motor areas of the upper limb and face: a brain stimulation study. Brain. (2019) 142:952-65. doi: 10.1093/brain/awz021
84. Breshears JD, Southwell DG, Chang EF. Inhibition of manual movements at speech arrest sites in the posterior inferior frontal lobe. Neurosurgery. (2019) 85:E496-501. doi: 10.1093/neuros/nyy592

85. Nelissen K, Vanduffel W. Grasping-related functional magnetic resonance imaging brain responses in the macaque monkey. J Neurosci. (2011) 31:82209. doi: 10.1523/JNEUROSCI.0623-11.2011

86. Rossi M, Fornia L, Puglisi G, Leonetti A, Zuccon G, Fava E, et al. Assessment of the praxis circuit in glioma surgery to reduce the incidence of postoperative and long-term apraxia: a new intraoperative test. J Neurosurg. (2018) 130:1727. doi: 10.3171/2017.7.JNS17357

87. Filevich E, Kühn S, Haggard P. Intentional inhibition in human action: the power of 'no'. Neurosci Biobehav Rev. (2012) 36:1107-18. doi: 10.1016/j.neubiorev.2012.01.006

88. Toma K, Honda M, Hanakawa T, Okada T, Fukuyama H, Ikeda $\mathrm{A}$, et al. Activities of the primary and supplementary motor areas increase in preparation and execution of voluntary muscle relaxation: an event-related fMRI study. J Neurosci. (1999) 19:3527-34. doi: 10.1523/JNEUROSCI.19-09-03527.1999

89. Shibasaki H. Human brain mapping: hemodynamic response and electrophysiology. Clin Neurophysiol. (2008) 119:731-43. doi: 10.1016/j.clinph.2007.10.026

90. Shibasaki H. Cortical activities associated with voluntary movements and involuntary movements. Clin Neurophysiol. (2012) 123:229-43. doi: 10.1016/j.clinph.2011.07.042

91. Krucoff MO, Rahimpour S, Slutzky MW, Edgerton VR, Turner DA. Enhancing nervous system recovery through neurobiologics, neural interface training, and neurorehabilitation. Front Neurosci. (2016) 10:584. doi: 10.3389/fnins.2016.00584

92. Krucoff MO, Wozny TA, Lee AT, Rao VR, Chang EF. Operative technique and lessons learned from surgical implantation of the neuropace responsive neurostimulation $®$ system in 57 consecutive patients. Oper Neurosurg. (2021) 20:E98-109. doi: 10.1093/ons/opaa300

93. Swann NC, de Hemptinne C, Miocinovic S, Qasim S, Ostrem JL, Galifianakis $\mathrm{NB}$, et al. Chronic multisite brain recordings from a totally implantable bidirectional neural interface: experience in 5 patients with Parkinson's disease. J Neurosurg. (2018) 128:605-16. doi: 10.3171/2016.11.JNS161162

94. Jeltema HR, Ohlerth AK, de Wit A, Wagemakers M, Rofes A, Bastiaanse $\mathrm{R}$, et al. Comparing navigated transcranial magnetic stimulation mapping and "gold standard" direct cortical stimulation mapping in neurosurgery: a systematic review. Neurosurg Rev. (2020) 1-18. doi: 10.1007/s10143-020-01397-x

95. Mandonnet E, Winkler P, Duffau H. Direct electrical stimulation as an input gate into brain functional networks: principles, advantages and limitations. Acta neurochir. (2010) 152:185-93. doi: 10.1007/s00701-009-0469-0

Conflict of Interest: The authors declare that the research was conducted in the absence of any commercial or financial relationships that could be construed as a potential conflict of interest.

Publisher's Note: All claims expressed in this article are solely those of the authors and do not necessarily represent those of their affiliated organizations, or those of the publisher, the editors and the reviewers. Any product that may be evaluated in this article, or claim that may be made by its manufacturer, is not guaranteed or endorsed by the publisher.

Copyright (C) 2021 Aaronson, Martinez Del Campo, Boerger, Conway, Cornell, Tate, Mueller, Chang and Krucoff. This is an open-access article distributed under the terms of the Creative Commons Attribution License (CC BY). The use, distribution or reproduction in other forums is permitted, provided the original author(s) and the copyright owner(s) are credited and that the original publication in this journal is cited, in accordance with accepted academic practice. No use, distribution or reproduction is permitted which does not comply with these terms. 